\title{
Querying Preschool Children Learning Foreign Language in China Based on Language Attrition and Cognition
}

\author{
Zhang Yuhuan ${ }^{1, a^{*}} *$ \\ ${ }^{1}$ School of Foreign Languages, China West Normal University, China \\ aemail: juliezhyh@163.com
}

Keywords: language attrition; cognition; preschool children

Abstract: With the development of language research many experts begin to realize it is valuable to do research on language attrition, which can benefit our foreign language education. This paper teases the study of language attrition with concrete materials in China and also analyzes the cognitive characteristics of preschool children in the process of language attrition. Then, it comes to the conclusion_— it is unworthy of advocating learning foreign language for preschool children in China on the basis of language attrition theory.

\section{Introduction}

Nowadays, the world is at the turning of various stages of economic, political, social, demographic and cultural transition. The emerging global economy and multi-outlet international market are both competitive and interdependent. Thus the future of the English language as a world language in the $21^{\text {st }}$ century is brighter. In China, the start of English classes in primary schools, which the Ministry of Education takes as one of the important contents of the curricular reform of our national basic education in the 21 st century, is of great significance. The Ministry of Education also issued a decision that, from the autumn of the year 2001, all primary schools in both cities and towns need to offer an English course ${ }^{[1]}$. In other words, such a phenomenon means that starting English as a child in China is more and more necessary. At the same time, some advertisements on starting English as a child emerge in an endless stream. Most experts ${ }^{[2][3]}$ are against teaching English in kindergarten, or even in primary schools in the condition of lacking target language environment. Meantime, language attrition takes place in the process of studying English for the preschool children and attracts more and more researchers. Many studies about second language attrition have been brought forward and Hansen and Reetz-Kurashige ${ }^{[4]}$ listed these achievement: English loss by Hebrew L1 speakers; French loss by Dutch native speakers and by English-speaking Canadians; German loss by Turkish native speakers, and by English native speakers; L2 Hindi-Urdu by English speakers; L2 Portuguese by English/Hebrew bilinguals, and L2 Spanish by English speakers. An increasing number of Chinese people learn English but relating language attrition material is seldom. Compared with the research on language attrition abroad, relating material home is so scarce. In addition, foreign language teaching specialists began with language attrition research in 2000s, far away from the time of starting the study of language attrition abroad. Zhong Shuneng ${ }^{[5]}$ and Cai Hansong, Zhou Rong ${ }^{[6]}$ are the experts who did research on language attrition in early time and they primarily reviewed the gained achievements of language attrition abroad and the value from the language attrition research. Li Ping, Zheng Shutang ${ }^{[7]}$ points out the relationship between language attrition and the ways of retention. Ni Chuanbin, Yan Junrong ${ }^{[8]}$ points out the factors analysis of language attrition, essential attributes of foreign language attrition by Ni Chuanbing ${ }^{[9]}$.

This thesis, on the basis of the experts' ideas, uses the theories of language attrition to explain why it is not wise for Chinese children to learn English in primary schools. What's more, this thesis will give some implications for Chinese English teachers on English-teaching especially on teaching English as a foreign language. 


\section{Definition of language attrition and its classification}

Language attrition describes the loss of, or changes to, grammatical and other features of a language as a result of declining use by speakers who have changed their linguistic environment and language habits. In such a situation there may, for example, be simplification in the tense system or in certain properties of subordinate clauses; some vocabulary items might fall into disuse and phonetic features may be restructured. These changes can be affected by factors in the speaker's environmentm and also by his or her attitudes, and processes of identification ${ }^{[10]}$. A typology presented by van Els ${ }^{[11]}$ will provide a clear perspective about it and van Els divided language attrition into four sorts based on (1) what is lost, either the first language(L1) or the second language(L2), and (2) where the language is lost, either in an L1 environment or an L2 environment(Table 1).

Table 1

\begin{tabular}{|l|l|}
\hline L1 in an L1 environment (Type 1) & L1 in an L2 environment (Type 2) \\
\hline L2 in an L1 environment (Type 3) & L2 in an L2 environment (Type 4) \\
\hline
\end{tabular}

(based on van $\mathrm{Els}^{[11]}$ )

This thesis refers toType 3 and focuses on second language attrition in the situation of lacking relative contexts in order to explain the problem that Chinese preschool children learning English in the condition of educational context. Yong children refer to children who are three to six or seven years old. The dividing line is according to the classification of international and national physical aspect and the reality that serving subjects in kindergarten in our own education are mainly about three to six years old $^{[12]}$. Then it analyzes some factors from cognition concerning it in Chinese context to explain that it is no good for children to learn English as a second language in China.

\section{Cognition}

One of the theories, associated with language attrition and language acquisition is Vygotsky's theory which implies that cognition development and the ability to use thought to control our own actions require first mastering cultural communication systems and then learning to use these systems to regulate our own thought processes ${ }^{[13]}$. It puts an emphasis on sociocultural nature of learning. In other words, when children work within their zone of proximal development, learning occurs. Moreover, even tasks take place within the zone of proximal development and they usually can not finish them by themselves. The children should depend on the assistance of more competent peers or adults. Higher mental functioning usually is in the existence of conversation and cooperation among individuals before it really exists in individual. That means as for Chinese preschool children learning English in China, they usually can not learn English by themselves and are not capable of gaining a high level of language proficiency in a short time. It is more likely for them to lose heart and confidence of learning a foreign language or it is easy that language attrition occurs according to their cognition of thinking the world.

Jean Piaget, an expert born in Switzerland, is the most influential developmental psychologist in the history of psychology. According to Piaget's theory, cognitive development can be divided into four stages: sensorimotor stage referring to ages from birth to two years, preoperational stage referring to ages from two to seven years, concrete operational stage referring to ages from seven to eleven years and formal operational stage from eleven to adulthood. The stage of preschool students exactly falls into the range of preoperational stage. During this stage, children have little difficulty in imitating or learning new things. They have absolute advantages of learning a language if they are in a state of natural language environment. From the point of pedagogics, the age from five to ten is the best period to nurture and train one's native language thinking. During this period, if native language is used in teaching, it is useful to cultivate and improve the level of one's native language. Moreover, it is also useful to develop one's ability of logic thinking.

Kang Lixin ${ }^{[14]}$ and Su Dingfang ${ }^{[15]}$ thought that preschool children at age of six or seven are apt to use one language during preoperational stage. If they learn another language at the moment, they not 
only feel depressed but also use the two obscuring languages to express their thoughts. It is harmful to children's development. However, preschool children are in the second stage that Piaget classified. If they do not persist in developing and training the cognitive ability of native language, the development of their language competence (including native language and foreign language competence) is usually effected. On the basis of low proficiency of native language to learn a foreign language, it not only is affective to the development of cognition but also is to hinder their improving foreign language level. In the situation of low foreign language proficiency, it is easy for attrition to take place, and the speed and the degree of language attrition quickens and become more badly. In that case, if children in the preoperational stage learn another language in the society of monolingual, it is better for them to use their native language ${ }^{[15][16]}$.

\section{Application}

So far it is obvious that more and more English teachers in China begin to be aware of the reality of Chinese preschool students learning: Chinese learners learning English separate themselves from natural language acquisition environment because they have no such English asquisition environment; besides, they lack the chances and impetus to use English like second language learners who live in the target language countries, so they are learning and forgetting. Most preschool English learners have no active learning interest and strong learning motivation. What's more important, foreign learners should grasp every access to use and reinforce foreign language during the incubation period. As for the foreign language teachers, they should reach a high level of their foreign language competence and know about pedagogical theories in order that they can help learner recognize language attrition and its connecting factors. They try their best to invent suitable environment for learners and use valuable teaching methods to help learners to gain high proficiency of their foreign language in order to avoid language attrition happening. The most significant for teachers is that they must concentrate on preschool children's pronouciations and cultivate the children's interest of learning English, not lexicon,forms and grammars. For compilers of teaching materials, they attempt to comply with the relationship of language attrition and its associating theories so that they can help teachers to improve efficiency of learning English and teaching English.

\section{Conclusion}

This paper falls into several parts. It starts with combing briefly the relative research on language attrition home and abroad on the one hand and lists the types of language attrition on the other hand. It points out that it is unworthy for chinese preschool children to learn English in Chinese context from the factor---cognition influencing language attrition. Without the English learning context, many factors will accelerate language attrition, so it is essential for English teachers in China to arouse the preschool children' English interest and emphasize their pronounciation. As a matter of fact, all the factors influencing language acquisition also are interference or acceleration for attrition. Factors influencing language attrition are sophisticated, so this paper does not take into account that all cases with different factors occur in language attrition. It is greatly beneficial to do researches on language attrition for foreign language teaching in China. It can be explored that the next researchers doing language attrition concentrate their attention on English course design and pedagogy in China which would be resistant to attrition.

\section{References:}

[1] Ministry of Education. (2001). English Curriculum Requirement in Elementary and Secondary Schools

[2]Gui Shichun. (1992). Querying the view_— Learning English as a child. Foreign Language

Teaching and Research, (4) 
[3] Zhao Shikai. (2002). Long path to English learning. Foreign Language, (5).

[4] Hansen, H. \& Reetz-Kurashige(1999). Investigating Second Language Attrition: An Introduction. Second Language Attrition in Japanese Context. New York and Oxford: Oxford University Press.

[5] Zhong Shuneng. (2003). The implication of language attrition study to foreign language teaching and research in China. Foreign Language Education,(1).

[6] Cai Hansong\&Zhou Rong. (2004). A survey of language attrition studies. Psychological Science,

[7] Li Ping\&Zheng Shutang. (2004). Language loss and retainment Shandong Foreign Language Teaching, (5).

[8]Ni Chuanbin\&Yan Junrong. (2006) Analysis of influence factors on foreign language attrition. Foreign Language Teaching and Research,(1).

[9] Ni Chuanbin. (2007). Essential attributes of foreign language attrition. Journal of Foreign Languages. (1)

[10] Monika S.Schmid Language attrition Cambridge: Cambridge Press 2011

[11] Van Els, T. (1986). An Overview of European Research on Language Attrition. Language Attrition in Progress. The Netherlands Foris Publication.

[12]Zhou Nianli. (2006). The Developmental Psychology of Preschool Children. Shanghai:East China Normal University Press.

[13] Slavin, R.E. (2004). Educational Psychology: Theory \& Practice. Beijing: Peking University Press.

[14] Kang Lixin. (2003). Foreign language and foreign language study. English Teaching and Research in Primary and Middle Schools, (6).

[15] Su Dingfang. (2004). Foreign Language Teaching Reform:Problems\&Countermeasures.

Shanghai: Shanghai Foreign Language Education Press

[16] Agulló, G. L. (2006). Overcoming age-related differences. Language learning, 4(60). 